\title{
Big and deep seated lipomatous tumours in children : results of surgical treatment
}

\author{
Emin Özkul, Serhat Elçı, Muhsin Elçı, Celil Alemdar
}

From the Department of Orthopaedics and Traumatology, Dicle University Medical Faculty, Diyarbakir, Turkey

The objective of the study is to evaluate results of our pediatric patients with big and deep-seated lipomatous tumors

Results of 32 children who underwent resection for $5 \mathrm{~cm}$ or larger and deep-seated lipomas were evaluated.

The mean age of the patients was 9.1 years (range, 0-16; 11 female/21 male), and median follow-up period was 3.21 years (range, 1-10 years). The median size of the excised tumour was $11 \mathrm{~cm}$ (range, 6-28 cm) in maximal dimension.

Big lipomas in children can be treated with marginal resection procedures without biopsy with lower complication and local recurrence ratio compared to adult patients with similar tumours in similar size and location.

Keywords : lipoma ; child ; surgery.

\section{INTRODUCTION}

Lipomas are the most common soft tissue tumours. Trauma, chronic irritation and congenital growth disorders play a role in its etiology. They often present as painless and slow-growing mass in subcutaneous or subfascial tissue, intramuscularly or between muscles. Superficial lipomas are usually small, mobile and soft masses, whereas deepseated lipomas can be so large that they can cause asymmetric appearance in extremities. Deep-seated lipomas are usually located proximal of extremities, such as in shoulders and calves. Their true incidence is unknown. Patients typically present in adulthood (at ages 40-60 years). They are rare in children (1-3).

When a lipomatous lesion is detected in children, the first diagnoses considered are lipoblastoma and its diffuse form lipoblastomatosis, which are $30 \%$ of lipomatous lesions in children. They are diagnosed usually in the first 3 years of life, slowly grow in a limit and mostly located in non-extremity localization (1-4).

Lipomas are encountered as an encapsulated region with same density with fatty tissue in plain radiography. In ultrasound, they appear as homogeneously hyperechoic mass. MRI is useful especially to evaluate deep-seated and bigger than

Emin Özkul ${ }^{1}$ MD, Ass. Professor, Orthopaedic surgeon,

- Serhat Elçi ${ }^{1}$ MD, Research Assistant, Orthopaedic surgeon,

Muhsin Elçi ${ }^{2} \mathrm{MD}$, General surgeon,

- Celil Alemdar ${ }^{3}$ MD, Ass. Professor, Orthopaedic surgeon, ${ }^{\prime}$ Department of Orthopaedics and Traumatology, Dicle University Medical Faculty, Diyarbakir, Turkey.

${ }^{2}$ Department of General Surgery, Siverek state hospital, Şanluurfa, Turkey

${ }^{3}$ Department of Orthopedics and Traumatology, Medipol University Medical Faculty, Istanbul, Turkey

Correspondence : Serhat Elçi, Dicle University Medical

Faculty, 21280, Diyarbakir, Turkey. Tel : 0090 4122488001/

4816, Fax : 00904122488111.

E-mail : serhatelci@gmail.com

- 2021, Acta Orthopædica Belgica. 
$5 \mathrm{~cm}$ tumours. These lesions are isoechoic with subcutaneous tissue in all sequences, and they rarely have contrast uptake. Biopsy is suggested when the mass contains necrosis, has high contrast uptake, heterogeneous or when not isoechoic with submucousal tissue (5).

Surgery is not needed as they are benign lesions and very common. Although indications for surgery are contentious, they are reasonable, which are as follows: masses bigger than $5 \mathrm{~cm}$, deep-seated or growing masses, masses have risk of malignity or which cause cosmetic concerns, functional disabilities or pain. Given their mostly benign nature, unplanned resection of lipomatous lesions is not a rare case, and it results in incomplete resection, morbidity and extremity amputations (1-7).

There are only a small number of papers about surgical treatment of deep-seated lipomas in children, and most of which are case reports. Thus, we know a little about their treatment results, recurrence, complication ratio and malignity risk. In this study, we aimed to evaluate our results for this kind of lipoma.

\section{MATERIALS AND METHODS}

Children who underwent surgery for lipomas in our centre between 2007 and 2018 were evaluated. Data were collected from hospital logs, operation notes, pathology reports and radiologic images. Patients who have histopathological diagnosis of lipoma, younger than 16 years of age and have 5 $\mathrm{cm}$ or bigger deep-seated lesion were included. Patients who have other affected tissues in their pathology report, older than 16 years old or have a mass smaller than $5 \mathrm{~cm}$ or superficially located mass were excluded.

Only 32 out of 78 patients who underwent lipoma surgery met the criteria. They have no congenital disease, deformity, syndrome or malformation.

Common clinical manifestation was a palpable mass that was known for a long time and causes mild function loss, waking up with pain and numbness.

In clinical evaluation, after the first examination anteriorposterior and lateral X-rays were performed. Then, all the patients were evaluated with ultrasound and MRI. If there is risk for malignity in the

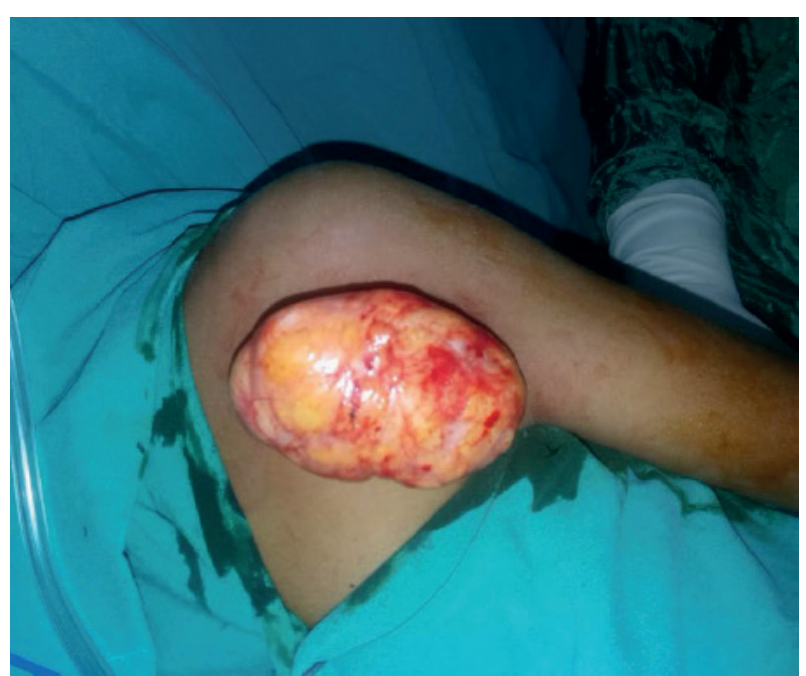

Figure 1. - An 11-year-old child with lipoma in his arm which underwent biopsy.

MRI (heterogeneous mass, tick septas, not to be in the same density with fatty tissue, high contrast uptake, necrosis), USG-guided fine-needle biopsy was performed. Marginal resection was performed after histopathologic confirmation. Other patients underwent surgery before histopathological diagnosis (Figure 1).

The patients were free to use their extremities hours after the surgery. The first control evaluation after the surgery was 10 days later. Then, they were evaluated every 6 months in the first year and annually in the following years. Control evaluation was physical examination and USG if necessary.

Statistical analysis (average, standard deviation, frequency) was carried out using SPSS (Statistical Package for the Social Sciences) Version 21.0 for Windows 7.

\section{RESULTS}

The mean age of the patients was 9.1 years (range, 0-16; 11 female/21 male), and median follow-up period was 3.21 years (range, 1-10 years). Out of the 32 masses evaluated, 11 were located in femur, 5 cruris, 4 dorsal area, 3 antebrachium, 2 gluteus, 2 axilla, 2 scapular area, 1 clavicle, 1 ankle and 1 anterior wall of chest. The localizations and sizes are summarized in Table 1. 
Table 1. - Patient characteristics

\begin{tabular}{|l|c|}
\hline \multicolumn{1}{|c|}{ Localization } & Number of patients \\
\hline Thigh & 11 \\
\hline Cruris & 5 \\
\hline Dorsal area & 4 \\
\hline Antebrachium & 3 \\
\hline Scapular area & 2 \\
\hline Gluteus & 2 \\
\hline Axilla & 2 \\
\hline Clavicular region & 1 \\
\hline Ankle & 1 \\
\hline Chest & 1 \\
\hline
\end{tabular}

\begin{tabular}{|l|c|}
\hline \multicolumn{1}{|c|}{ Mass size } & Number of patients \\
\hline $5-7 \mathrm{~cm}$ & 15 \\
\hline $7-9 \mathrm{~cm}$ & 6 \\
\hline $9-10 \mathrm{~cm}$ and above & 6 \\
\hline $10 \mathrm{~cm}$ and above & 5 \\
\hline
\end{tabular}

USG-guided needle biopsy was performed for 6 masses that MRI was suspicious for malignancy. After the biopsy, resection was done. There was no need for a second biopsy. Marginal resection was performed before histopathological investigation in other cases.

In macroscopy, there was mature fatty tissue that was lobulated by septas and covered by a fibrous capsule with well-defined borders. The median size of the excised tumour was $11 \mathrm{~cm}$ (range $6-28 \mathrm{~cm}$ ) in maximal dimension.

There were wound complications in 5 patients ( 1 hematoma and 4 serous leakage), and all of them recovered simply with antibiotherapy and dressing. Even though the lesions were big and 7 of them were in relation with nerves, there was no neurovascular injury (Figure 2). After the surgery, all the symptoms were gone, and no recurrence occurred.

\section{DISCUSSION}

Lipomas are the most common soft tissue tumours. However, their true incidence is unknown due to conservative follow-up. Deep-seated lipomas are seen mostly in adults and are treated with surgery. These lipomas which are $1 \%$ of lipomas, are resected with indications, such as malignancy risk, cosmetic concerns, function disorders and pain $(1-3,8,10)$.

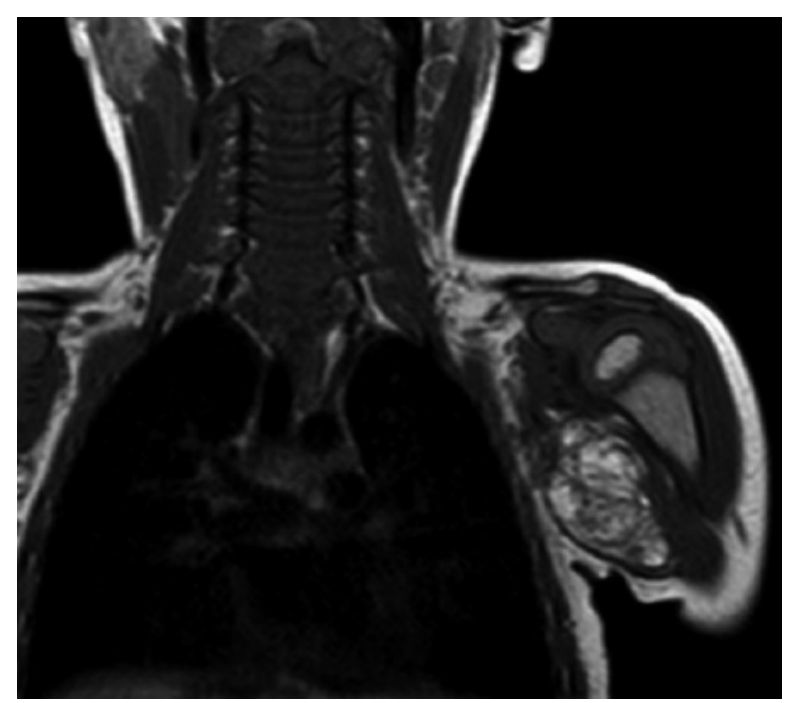

Figure 2. - A 3-year-old patient with a tumour invading median nerve.

Lipomatous tumours have subgroups, such as pleomorphic lipoma, spindle cell lipoma, intramuscular lipoma and myolipoma. Deep-seated, $\geq 5 \mathrm{~cm}$, infiltrating lipomas can be malign (13-14). Therefore, sometimes, differential diagnosis is difficult. Diagnosis is mostly possible without a biopsy because of their benign nature. However, when it is not possible to exclude malign diagnoses despite use of USG and MRI (9), it is necessary to perform a biopsy for masses that grow rapidly and with a suspicious appearance in MRI. Core biopsy provides true diagnosis at $73 \%(11,12)$. In this method, the risk for wound problems is less and it is easier to take biopsies from different localizations compared to open biopsy. If the procedure is USGguided, the biopsy has higher success ratio $(11,12)$. In this study, we performed USG-guided biopsy for the 10 patients before resection.

Tumors most likely to be malignant (Deepseated, $\geq 5 \mathrm{~cm}$, infiltrating tumours) usually are located in bigger muscle groups in extremities, such as the trapezius, deltoid, latissimus dorsi, pectoralis, gluteus maximus and gastrocnemius. Some of them get liposarcoma diagnosis (14). Malignancy risk is pretty low for tumours smaller than $3 \mathrm{~cm}$. While the sizes were similar in our study, none of them got liposarcoma diagnosis. Therefore, we think that tumour size and location are not sufficient criteria of malignancy in children (Figure 3). 


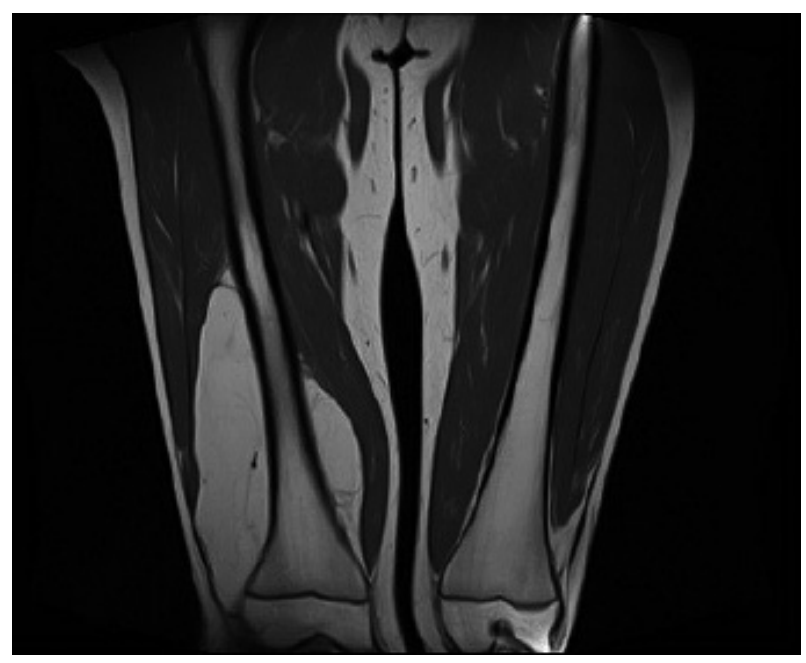

Figure 3. - A 14-year-old patient with huge lipoma in the thigh.

Marginal resection is a sufficient treatment for lipomas, with a recurrence risk of 5\% after the resection. This ratio is higher if the lipoma is located between muscle fibers. Although we did not perform extensive resection for any case, no recurrence was seen.

Deep-seated tumours grow towards softer tissue and remain within anatomic compartments. Some-times, they can be close to a neurovascular bundle. If the lesion is multilobular, radiology exams, such as MRI, are necessary for evaluation of locoregional involvement and tumour extension (13-15). Therefore, in this study, all of the patients were evaluated with MRI before the surgery. No neurovascular injury occurred in 7 cases in which the mass was close to various nerves and vessels.

Lipomatous tumours are rarely multiple (5\%). Multiple lipomas are especially found on the upper extremities and upper back, and $1 / 3$ of them have hereditary conditions (16). There was no multiple case in our study.

The evidence provided by this study is weak as it is retrospective in nature and the patient number is low due to the low incidence of big lipomas in children.

Deep-seated lipomas are rare in children compared to adults. Although they can be in huge sizes, almost all of them are benign. Biopsy is also rarely necessary for diagnosis before surgery and complication, and local recurrence ratio is low.

\section{REFERENCES}

1. Johnson CN, Ha AS, Chen E, Davidson D. Lipomatous Soft-tissue Tumors. J Am Acad Orthop Surg. 2018 ; 15 ; 26 : 779-788.

2. Miller GG, Yanchar NL, Magee JF. et al. Tumor karyotype differentiates lipoblastoma from liposarcoma. $J$ Pediatr Surg. 1997 ; 32 : 1771-1772.

3. Goldblum JR, Folpe AL, Weiss WS. Benign lipomatous tumors. Enzinger \&Weiss's Soft Tissue Tumors, ed 6. Philadelphia, PA, Elsevier. 2014 ; 443-483.

4. Serpell JW, Chen RYY. Review of large deep lipomatous tumours. ANZ J. Surg. 2007 ; 77 : 524-529

5. Papp BDF, Khanna AJ, Mccarthy EF, et al. Magnetic resonance imaging of soft-tissue tumors : Determinate and indeterminate lesions. J Bone Joint Surg Am. 2007 ; 89 : 103-115.

6. Tedesco NS, Henshaw RM. Unplanned resections of sarcoma. J Am Acad Orthop Surg. 2016 ; 24 : 150-159.

7. Weiss S, Goldblum J. Liposarcoma. Enzinger and Weiss's Soft Tissue Tumours, 4th edn. St. Louis : Mosby. 2001 ; 641-693.

8. Myhre-Jensen O. "A consecutive 7-year series of 1331 benign soft tissue tumours. Clinicopathologic data. Comparison with sarcomas," Acta Orthop Scand. 1981 ; $52: 287-293$.

9. Sommerville S, Patton J, Luscombe J, Mangham D, Grimer R. Clinical outcomes of deep atypical lipomas (well-differentiated lipoma-like liposarcomas) of the extremities. ANZ J. Surg. 2005 ; 75 : 803-806.

10. Rozental T, Khoury L, Donthianeni-Rao R, Lackman R. Atypical lipomatous masses of the extremities. Outcomes of surgical treatment. Clin. Orthop. $2002 ; 398$ : 203-211.

11. Serpell J, Pitcher M. Pre-operative core biopsy of softtissue tumours facilitates their clinical management. $A N Z$ J. Surg. $1998 ; 68: 345-349$.

12. Mankin H, Lange T, Spanier S. The hazards of biopsy in patients with malignant primary bone and soft tissue sarcomas. J. Bone Joint Surg. Am. 1982 ; 64 : 1121-1127.

13. G. P. Dionne and T. A. Seemayer, "Infiltrating lipomas and angiolipomas revisited," Cancer. 1974 ; 33 : 732-738.

14. Henze J, Bauer S. "Liposarcomas," Hematol Oncol Clin N Am. $2013 ; 27$ : 939-955.

15. Han HH, Choi JY, Seo BF, Moon SH, Oh DY, Ahn ST, Rhie JW. Treatment for Intramuscular Lipoma Frequently Confused with Sarcoma: A 6-Year Restrospective Study and Literature Review. Biomed Res Int. 2014 ; 10 : 1-7.

16. Fletcher CDM, Bridge JA, Hogendoorn PCW, Mertens F. Adipocytic tumours. WHO Classification of Tumours of Soft Tissue and Bone, ed 4. Herndon, VA, Stylus Publishing. 2013 : 1942. 